
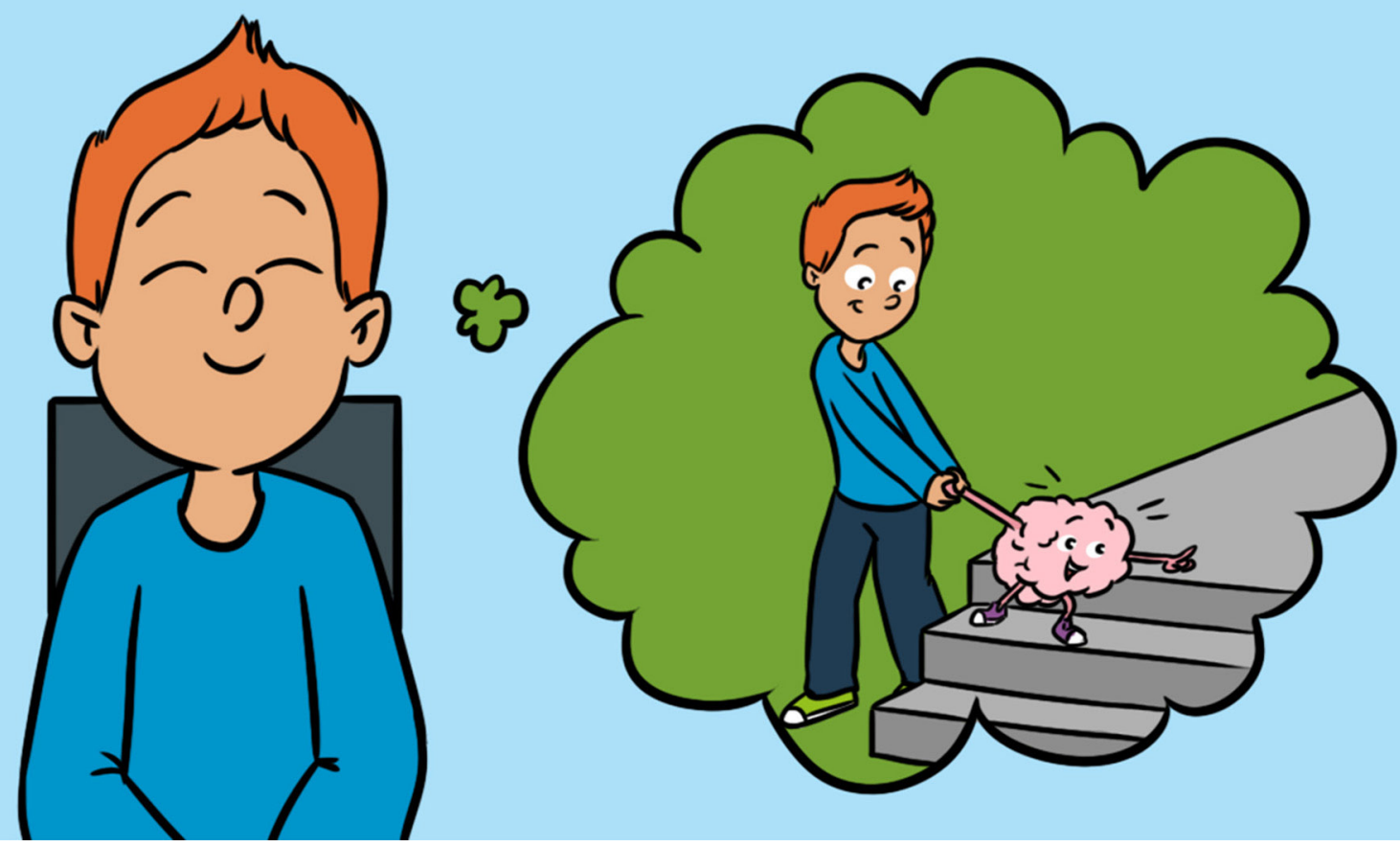

\title{
A GYM WORKOUT FOR YOUR BRAIN: HOW MINDFULNESS CAN HELP IMPROVE MENTAL HEALTH
}

\section{Ben Isbel*}

Sunshine Coast Mind and Neuroscience-Thompson Institute, University of the Sunshine Coast, Sippy Downs, QLD, Australia

\section{YOUNG REVIEWERS:}



MATTHEW

FLINDERS

ANGLICAN

COLLEGE

AGES: $14-15$
You probably know that going to the gym to exercise is good for your body. Exercise keeps us fit and healthy. Did you know that you can also exercise your mind to keep it fit and healthy? Mindfulness training is just like taking your brain to the gym for a workout. When we practice mindfulness, we are training our attention to stay in the present moment instead of wandering off with our thoughts into the past or the future. By keeping our attention in the present, and bringing it back each time it wanders, we are training the brain networks that we use to control our attention. This type of training can improve our mental health, just like physical exercise improves our physical health.

\section{DOES MINDFULNESS MEAN MY MIND IS FULL?}

Have you ever been so deep in thought that you did not hear someone calling your name? At times like these, our minds are full of thoughts 


\section{MINDFULNESS}

The ability to pay attention to the present moment, without judgment or reaction

\section{ATTENTION}

The brain's ability to focus on one thing out of a wide range of objects.

\section{Figure 1}

When we bring full awareness to what is happening in the mind we have mindfulness. and we are not aware of what is going on around us. Often, we are busy thinking about what is going to happen later, thinking about what happened earlier, or thinking about what is happening now. It can certainly seem like our minds are full of thoughts! But that is not what mindfulness means. Mindfulness means being aware of what is happening now, without getting lost in all of those thoughts. Mindfulness helps us become more aware of what is going on both outside and inside of ourselves, without being distracted by our thoughts. With mindfulness, we can be fully aware of our minds (see Figure 1).

\section{EXERCISE FOR THE MIND}

Just as we need to exercise our bodies to stay physically healthy, exercising our minds can keep us mentally healthy, too. Mindfulness involves training our attention to stay in the present moment, rather than following our thoughts into the past or future. The same way we do certain exercises to strengthen our body's muscles, with mindfulness we train the brain's muscle-attention.

Attention is the brain's way of selecting one thing to focus on out of the wide range of things in the environment. The brain is constantly receiving information about the world around us from our five senses, as well as interpreting that information using lots of thoughts. There is so much going on in the environment, but we often need to select one thing to focus on, without getting distracted. Attention's job is to keep that one thing in mind, so we can focus on it. Attention is one of the most important brain functions. When attention does not work well we have lots of difficulties, such as attention deficit hyperactivity disorder (ADHD). In ADHD, people have trouble keeping their minds on one task, which makes it hard to concentrate when trying to solve a math problem at school, for example.

\section{Mind + full awareness}

\section{Mind + fultawareness}

\section{Mindfulness}


When you focus on something, you are using networks made up of brain cells called neurons. When you do physical exercise to strengthen a muscle, you train that muscle by repeating the exercise again and again. In mindfulness, you can target these brain networks by making your attention stay on one thing without getting distracted. And when you do get distracted, you bring your attention back again and again. It is like a gym workout for your brain! Scientists have discovered that this kind of exercise can benefit mental health [1].

\section{MINDFULNESS}

Let us try a mindfulness exercise right now.

Start by sitting down either on the floor or on a chair with your back nice and straight. As you sit, just relax. Be aware of your body as you sit still. While you are sitting still, notice the rising and falling of your belly as you breathe in and out. Do not try to make your breath deeper or longer, but just let it be. Just feel it. Can you feel the sensations of movement as your belly goes up and down with the breath? Try not to think about these movements. Just pay attention to the sensations of the rising and falling of the belly as you breathe in and out. Without following thoughts as they arise, just stay with the feeling of the rising and falling.

It would not be long before you start thinking of something other than your breath. Your attention will want to follow a thought, since watching the breath can be pretty boring! We usually like to pay attention to things that are exciting. But, by stopping your attention from following thoughts and just returning it to the rising and falling of your breath, you are training several attentional networks in your brain.

- When you focus on the breath, you use a brain network for focused attention.

- When you notice a wandering thought, you use a brain network for detecting distraction.

- When you stop that wandering thought, you use a brain network to prevent your attention from following that thought.

- When you return your attention back to the breath, you use a brain network for redirecting attention.

When we practice mindfulness, we are always getting distracted from the breath, so we have to activate all of these networks over and over again (see Figure 2). This is why mindfulness can seem like hard work. Because it is! We are really giving the brain a workout when we try to keep our attention on the breath. 
Figure 2

The process of controlling attention during mindfulness practice. First, try to follow the feeling of your breath. When your mind wanders, notice that is happening and bring the attention back to the breath. Repeat this again and again! It is like a gym workout for your brain!

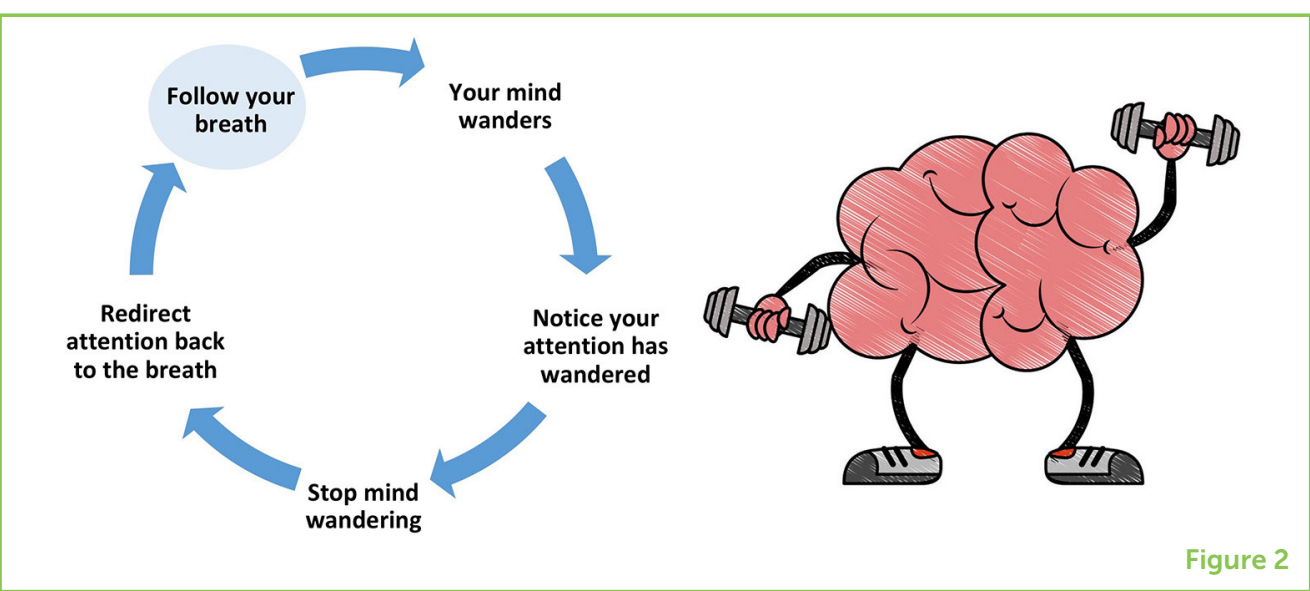

An important part of mindfulness is paying attention without reacting to what is going on. It is easy to get frustrated by your wandering mind. While you are trying to follow the rising and falling of the breath, just pay attention without reacting to what you are experiencing. Do not worry about whether it is easy or difficult. If you react to what is happening, you are just thinking even more thoughts! Just let your attention rest on the breath. And when it wanders, bring it back each time.

Can you do it for 1 min? Have a try!

\section{WHAT HAPPENS TO A WANDERING MIND?}

Scientists have discovered that the more our thoughts wander the greater chance we have of being unhappy [2]. When we keep thinking about something bad that happened in the past, we could become depressed. If we keep worrying about something bad that might happen in the future, we could become anxious. Being depressed and anxious occur when our thoughts take us away from what is happening right now, into the past or the future.

Neuroscientists (scientists who study the brain) have found that depression and anxiety are associated with changes in the brain. Scientists can measure the activity of neurons in the brain using a device called an electroencephalograph, or EEG. An EEG measures brain activity by recording the electrical signals produced by the neurons (see Figure 3).

These electrical signals are measured using electrodes placed on the scalp. If electrical activity is measured on both sides of the brain, neuroscientists can see if the activity is the same on both sides. If there is asymmetry (lack of equality) between the two sides of the brain, neuroscientists can see if there is relatively more right-sided or left-sided brain activity. 


\section{Figure 3}

This girl is having her brain activity measured by EEG. The wires in this cap are connected to small electrodes that record the electrical activity produced by neurons in the brain. In this way, scientists can measure whether there is more left or right sided brain activity. Greater left-sided brain activity is associated with positive feelings.

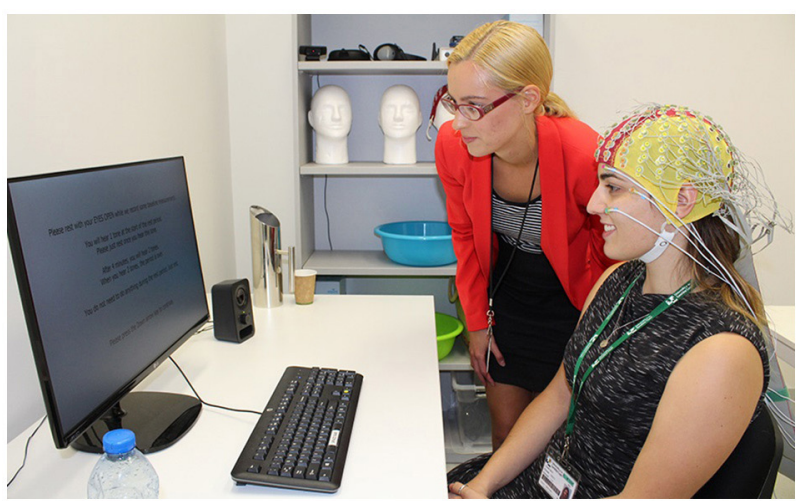

Figure 3

Studies have shown that greater left-sided brain activity is associated with positive feelings and behavior, while greater right-sided brain activity is associated with more negative feelings and behavior [3]. People with depression and anxiety have been shown to have higher levels of right-sided brain activity than people without these conditions [4].

\section{PAYING ATTENTION TO THE PRESENT IS GOOD FOR US}

By now, you might be wondering why you have to pay attention to the breath when you are practicing mindfulness. The breath has one very special feature. It only occurs now, in the present moment. If you are paying attention to your breath, you must be paying attention to what is happening right now. When your thoughts wander, you lose the present moment. But you can always come back to the present by remembering the breath.

Scientific studies are beginning to show that mindfulness practice may result in increased left-sided brain activity [5]. This increase in left-sided activity may also be accompanied by more positive feelings and well-being. This is really good news, because it means that we can change our brains just by training the way we pay attention. By training our attention to stay in the present moment, we can keep our minds from running off into the past and the future and worrying about all of those things. And this may change our brains in ways that help us feel better.

\section{REFERENCES}

1. Gotink, R. A., Chu, P., Busschbach, J. J. V., Benson, H., Fricchione, G. L., and Hunink, M. G. M. 2015. Standardised mindfulness-based interventions in 
healthcare: an overview of systematic reviews and meta-analyses of RCTs.

PLOS ONE 10:e0124344. doi: 10.1371/journal.pone.0124344

2. Killingsworth, M. A., and Gilbert, D. T. 2010. A wandering mind is an unhappy mind. Science 330:932. doi: 10.1126/science.1192439

3. Tomarken, A. J., Davidson, R. J., Wheeler, R. E., and Doss, R. C. 1992. Individual differences in anterior brain asymmetry and fundamental dimensions of emotion. J. Pers. Soc. Psychol. 62:676-87. doi: 10.1037/00223514.62.4.676

4. Adolph, D., and Margraf, J. 2017. The differential relationship between trait anxiety, depression, and resting frontal $\alpha$-asymmetry. J. Neural Transm. (Vienna) 124:379-86. doi: 10.1007/s00702-016-1664-9

5. Zhou, R., and Liu, L. 2017. Eight-week mindfulness training enhances left frontal EEG asymmetry during emotional challenge: a randomized controlled trial. Mindfulness 8:181-9. doi: 10.1007/s12671-016-0591-z

SUBMITTED: 24 September 2018; ACCEPTED: 15 February 2019; PUBLISHED ONLINE: 01 March 2019.

EDITED BY: Daniel F. Hermens, Sunshine Coast Mind and Neuroscience Thompson Institute, University of the Sunshine Coast, Australia

CITATION: Isbel B (2019) A Gym Workout for Your Brain: How Mindfulness Can Help Improve Mental Health. Front. Young Minds 7:34. doi: 10.3389/ frym.2019.00034

CONFLICT OF INTEREST STATEMENT: The author declares that the research was conducted in the absence of any commercial or financial relationships that could be construed as a potential conflict of interest.

COPYRIGHT @ 2019 Isbel. This is an open-access article distributed under the terms of the Creative Commons Attribution License (CC BY). The use, distribution or reproduction in other forums is permitted, provided the original author(s) and the copyright owner(s) are credited and that the original publication in this journal is cited, in accordance with accepted academic practice. No use, distribution or reproduction is permitted which does not comply with these terms.

\section{YOUNG REVIEWERS}

\section{MATTHEW FLINDERS ANGLICAN COLLEGE, AGES: 14-15}

Matthew Flinders Anglican College young reviewers are keen budding scientists who enjoy taking on challenges. They are a collaborative bunch of young minds, with shared interests in science, music, and sport. This group of young reviewers thoroughly enjoys being part of Frontiers for Young Minds and is excited to be involved in how science is being communicated and shaped. 


\section{AUTHOR}

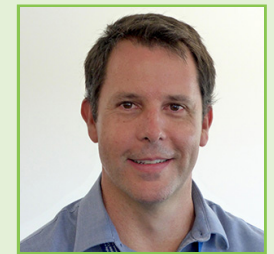

\section{BEN ISBEL}

I am a Neuroscientist interested in ways that we can improve attention and cognition using mindfulness training. I work at the Sunshine Coast Mind and NeuroscienceThompson Institute in Australia, where I specialize in EEG techniques to study the brain. *ben.isbel@research.usc.edu.au 